\title{
Emissions of e-mobility
}

E-mobility is treated as emission-free. Generally, this sentence can only be true in a very small range. Namely, about selected parameters and in a very limited area. An example of this is the measurement of $\mathrm{CO}_{2}$ emissions in the immediate vicinity of BEV (battery electric vehicle). The situation can change dramatically if you take into account the emissions in the energy production necessary for car traffic. This work presents this issue taking into account the energy mix in the various countries of the European Union. Simulation research shows that there are already countries in the EU where the operation of electric vehicles makes sense. Especially when it concerns $\mathrm{CO}_{2}$ emissions. Emissions below the standards for 2025 can be obtained there. Unfortunately, in most EU countries, the operation of $\mathrm{BEV}$ is associated with increased (in relation to present-day) $\mathrm{CO}_{2}$ emissions. Without changing the energy policy, and in particular the energy mix, introducing e-mobility is problematic.

Key words: e-mobility, emissions

\section{Introduction}

E-mobility is treated as emission-free. Generally, this sentence can only be true in a very small range. Namely, about selected parameters and in a very limited using area. An example of this is the measurement of $\mathrm{CO}_{2}$ emissions in the immediate vicinity of BEV (battery electric vehicle) . The situation can change dramatically if you take into account the emissions in the energy production necessary for car traffic. This work presents this issue taking into account the energy mix in the various countries of the European Union. In Figure 1 is the energy by sources in EU countries given.

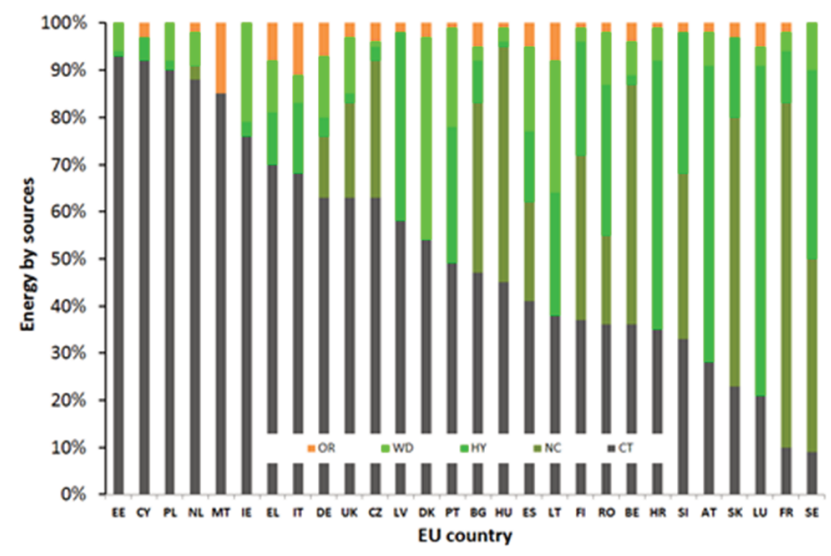

Fig. 1. Energy by sources in some countries in Europe. (CT - conventional thermal, NC - nuclear, HY - hydro, WD - wind, OR- other resources, based on [1])

As can be seen in the European Union there is a strong diversification of sources of electricity. In some countries the dominant role is played by conventional sources, while in others the acquisition of electricity from renewable resources is definitely more important.

But nowhere has such a state of affairs been achieved that all electricity comes from renewable resources.

Today's electricity production covers today's needs. E-mobility is "new" in energy demand. Hence the question arises from which energy sources e-mobility will be powered, and in particular how it will affect emissions.

When discussing emissions, the most common issues are global emissions such as $\mathrm{CO}_{2}$ emissions. However, from the point of view of people, also important are the emissions of $\mathrm{PM}$ - solid particles (e.g. from grated tires or roadways), $\mathrm{NO}_{\mathrm{x}}$ - nitrogen oxides, $\mathrm{SO}_{\mathrm{x}}$ - sulfur oxides or $\mathrm{HC}$ - hydrocarbons.

Generally, emissions are also divided into so-called low emissions (smog) and high emissions.

Such a division may perhaps make sense, but each emission has a negative impact on people and the environment, and unfortunately there is no exception.

The problem of emission assessment is therefore multifaceted. This work is devoted to the global approach to emission issues by assessing $\mathrm{CO}_{2}$ emissions during the operation of electric vehicles. It goes without saying that with the emission of $\mathrm{CO}_{2}$, the emission of the above compounds will follow. These emissions are not linearly correlated. This will have to be subjected to a deeper analysis, for which it is also necessary to develop appropriate methods, and this publication is also devoted this issue to .

The issue of emissions from e-mobility can be considered in static terms (thus analyzing what is happening at a given moment) or in dynamic terms, thus as a function of time (for example including the increase in the number of electric vehicles).

In this work the issue was treated statically. But even in this case there are issues that cannot be omitted.

Such issue is, for example, the issue of energy import and export between countries. In one country, more "pure" energy can be produced and this energy is exported to a country that produces "dirty" energy. Then, in the importing country, "more pure" energy is used. Of course, the opposite is also possible. This undoubtedly affects energy LCA in individual countries.

An important factor affecting energy LCA is also the use of electricity, by BEVs, in individual countries. The issue here is a way of assessing the use of electricity during the natural exploitation of vehicles.

These issues are (somewhat) more accurately presented in this publication.

\section{Well-to-Wheels methodology}

The methodology presented here as chapter 2, 3 and 4 are on basis of [2] The methodology considered in this article is Well-To-Wheel (WTW) detailed in version 4a of the [3] 
This approach allows quantifying the amount of energy required for greenhouse gas emissions resulting from the production, transport and distribution of conventional and alternative fuels for road transport (Well-To-Tank, WTT), as well as for quantifying the performance of various drive units (Tank- To-Wheels, TTW).

Compared to the Comprehensive Attribution Life Cycle Assessment (LCA) approach, WTW considers part of the LCA impact category "energy consumption" and "greenhouse gas emissions".

In the WTW approach, emissions related to the construction of equipment, maintenance and decommissioning of fuel and vehicle production plants, including material cycles, are not taken into account. Water pollution requirements or emissions are not taken into account if they do not affect GHG emissions. GHG included is carbon dioxide, methane and dinitrogen monoxide. The WTW methodology can be seen as a simplified LCA, designed to assess only energy consumption and greenhouse gas emissions from the use of road transport fuels.

\section{CI - Carbon intensity of electricity}

Carbon intensity of electricity can be defined as the GHG emitted for producing or using a certain amount of electricity as shown in equation (1):

\section{$\mathrm{CI}=\mathrm{GHG}$ emissions/electricity amount}

Since GHG emissions are expressed in grams [g] of $\mathrm{CO}_{2}$ equivalent and the electricity (e.g. produced or using) is expressed in [kWh] the consequent carbon intensity (CI) is usually expressed in $\left[\mathrm{gCO}_{2} \mathrm{eq} / \mathrm{kWh}\right]$.

In this paper it will be report the carbon intensities for all the following stages of the electricity pathway: gross production, net production, electricity traded, supply posttrade, consumed at high voltage after transmission, consumed at medium voltage after distribution and consumed (by the most of users) at low voltage.

The JEC WTW analysis considers GHG emissions occurring in two main steps, that is: combustion emissions occurring when fuels are burnt and upstream emissions.

The upstream emissions are caused by the extraction, refining and transport of the fuels to the power plants. For other fuels and renewables such as peat, municipal and industrial wastes, hydropower, geothermal, solar, wind and tidal power the upstream emission factors were considered equal to zero.

For nuclear power plants the approach in use by main international statistical bodies (IEA, EUROSTAT, IAEA) has been adopted. Converting the electric energy produced from nuclear or renewables into an equivalent primary energy have a average thermal efficiency (e.g. IAEA, 2007) equal $33 \%$.

\section{Electricity trade and carbon intensity}

The carbon intensity of the electricity consumed in a country depends also on the CI and amount of electricity traded with other countries. Logically, electricity imported in a country embeds also the GHG necessary for its production, so a WTW (or LCA) calculation aiming at realistically representing the carbon intensity of electricity consumed, should also consider the trade aspect, especially for countries having high electricity imports.

The electricity supplied (ElS) to a national network, considering the trade, is defined by the IEA with the equation (2):

$$
\mathrm{ElS}=\mathrm{El}_{\text {net production }}-\mathrm{El}_{\text {Pumping }}+\mathrm{EL}_{\text {Imports }}-\mathrm{El}_{\text {Exports }}
$$

For all these terms presented in equation (2) it can be used the IEA statistical data.

In order to calculate the CI of the electricity supplied (post trade) in a country it is possible to use equation (1), considering in the denominator the result of equation (2), and in the numerator the value of total GHG emissions embedded in the electricity supplied, calculated according to equation (3):

$$
\mathrm{GHG}_{\text {Total }}=\mathrm{GHG}_{\text {Combustion }}+\underset{\mathrm{GHG}_{\text {Imported }}}{\mathrm{GHstream}_{\text {Ifted }}-\mathrm{GHG}_{\text {Exported }}+}
$$

Combustion and upstream GHG emissions are the same values used to calculate the CI of electricity produced in each country, the exported GHG is simply the product between the CI of electricity traded multiplied by the Upstream and combustion emissions

Imported GHG emissions can be treated as

$$
\begin{array}{r}
\mathrm{GHG}_{\text {Import }}=\mathrm{S}\left(\mathrm{GHG}_{\text {Imoirt from i-th Country }} \times \mathrm{CI}_{\text {Elproduction in i-th }}\right. \\
\text { Counttry }
\end{array}
$$

where for each country it is necessary to consider the sumproduct of all the amount of electricity traded (El. Import from Country "i") and the respective Carbon Intensities (CI El traded Country "i").

Table 1 shows the results of calculations for the different values of carbon intensity, calculated for each EU country (for the year 2013).

Table 1 Carbon intensity (CI) in EU countries in several steps of production trading and supplied

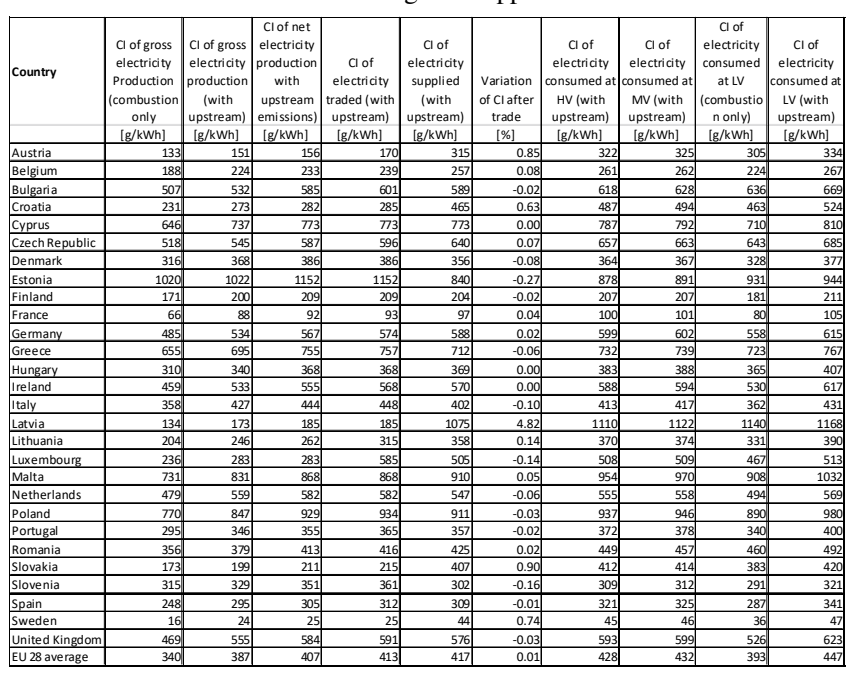

The order of the countries listed in Table 1 is the same as shown in Fig. 1. Countries were presented according to the decreasing share of non-renewable sources in the generation of electricity.

Interesting are the results presented in Fig. 2. The results from Table 1 have been added to the results presented 
in Fig. 1. The percentage of electricity from combustion processes (in individual EU countries) are compared as well with the $\mathrm{CO}_{2}$ mass emissions (per kilowatt-hour) by electricity production and its use (together with import) in every country.

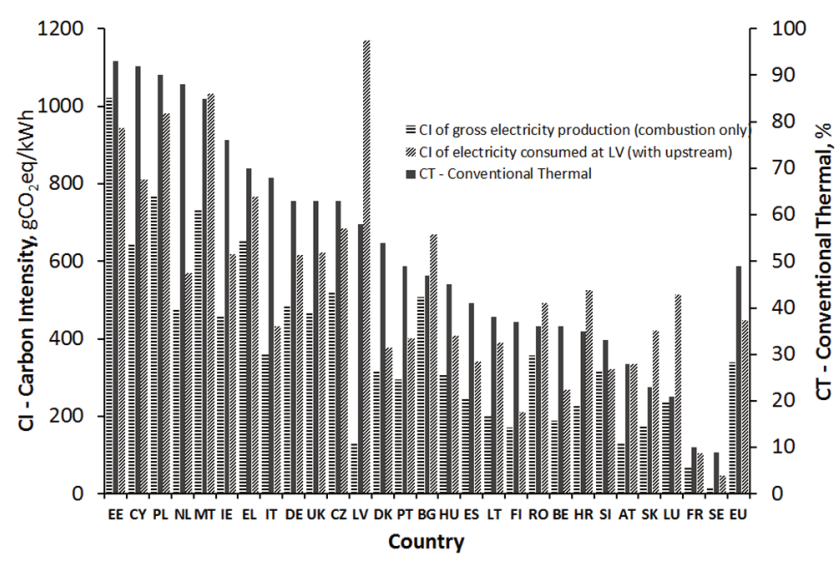

Fig. 2. Carbon intensity by production and use of electricity in EU countries

The data primarily indicate that centralized electricity generation and distribution systems cause large losses in energy transmission - which means a significant increase in specific $\mathrm{CO}_{2}$ emissions (in $\mathrm{g}_{\mathrm{eq}} / \mathrm{kWh}$ ).

Electricity imports (especially if this energy is produced in the exporter's country from non-renewable resources), can lead to a significant increase in $\mathrm{CO}_{2}$ emissions "in the country that imports" electricity.

\section{Electricity use by BEV's operation}

For the correct emission assessment related to the production and use of energy in e-mobility, it is necessary to know the electricity demand of electric vehicles (BEVs)

Based on the assumption that the emission related to the supply of electricity to the vehicle's charging point is known (Table 1), it is necessary to assess how much of this energy must be used to drive at a particular section of road.

The necessary data can be obtained from the appropriate tests (in the EU previously NEDC test and currently WLTP [4]) but it is known that the test results do not coincide with the data from natural exploitation [11]

Therefore, it is crucial to assess the operational energy "consumption" in the natural exploitation of vehicles (energy cannot be consumed - possible is the change of its form only - but as parallel to the historical term "fuel consumption" in following will be the term "energy consumption" used).

It seems that for assessing the energy consumption in natural exploitation of BEVs in particular is the theory of cumulative energy consumption useful.

The theory of cumulative energy consumption was originally developed (as author work) to assess the cumulative consumption of fuel in the natural exploitation of ICE vehicles [5].

The usefulness of the theory has been repeatedly confirmed, also when powering the engines with various fuels [6-9]. The main applications of the theory have been found in assessing the fuel consumption of urban bus fleets. Spe- cial software has been created for proper data collection (for obvious reasons, it will not be described here).

The energy consumption of a car in its natural exploitation is a random process. Energy is consumed in the "quantum" model. Energy quanta have a random size. Also, the time between the quantum of energy consumed is random.

Total amount of quanta of energy supplied to the car engine in the its operating period is called as cumulative energy consumption.

Energy quantum summation leads to determining the cumulative energy consumption. Energy consumption caused by the time $t$ of the engine work. can be designated as

$$
\operatorname{CFC}_{\mathrm{c}}\left(\mathrm{t}_{\mathrm{d}}\right)=\sum_{\mathrm{i}=1}^{\mathrm{n}\left(\mathrm{t}_{\mathrm{d}}\right)} \mathrm{q}_{\mathrm{i}}=\mathrm{n}\left(\mathrm{t}_{\mathrm{d}}\right) \cdot \overline{\mathrm{q}}\left(\mathrm{t}_{\mathrm{d}}\right)
$$

where: $\mathrm{CFC}_{c}\left(t_{d}\right)$ - the cumulative energy consumption to the mileage $t_{d}, t_{d}-$ mileage

$\mathrm{q}_{\mathrm{i}}$ - i-th quantum of energy, $\overline{\mathrm{q}}\left(\mathrm{t}_{\mathrm{d}}\right)$ - the average size of the quantum of energy used to the mileage $t_{d}, n\left(t_{d}\right)-$ number of the energy quantum used to the mileage $t_{d}$.

To know the cumulative energy consumption to the mileage $t_{d}$ should be familiar with the average size of the quants and the number of quantum of consumed energy to that mileage.

The way to reach these values has been presented in [5].

These publications also provide a way to obtain a mathematical model describing the cumulative energy consumption as a function of the vehicle's mileage.

The model has a form

$$
\operatorname{CFC}_{\mathrm{c}}\left(\mathrm{t}_{\mathrm{d}}\right)=\sum_{\mathrm{i}=1}^{\mathrm{n}\left(\mathrm{t}_{\mathrm{d}}\right)} \mathrm{q}_{\mathrm{i}}=\mathrm{n}\left(\mathrm{t}_{\mathrm{d}}\right) \cdot \overline{\mathrm{q}}\left(\mathrm{t}_{\mathrm{d}}\right)=\mathrm{ct}_{\mathrm{d}}^{(\mathrm{a}+1)}
$$

The intensity of energy consumption is a mathematical derivative from equation (6), so it has a form

$$
\mathrm{CFC}^{\prime} \mathrm{c}=\operatorname{ICFCc}\left(\mathrm{t}_{\mathrm{d}}\right)=\frac{\mathrm{dCFC}_{\mathrm{c}}}{\mathrm{dt}}=\mathrm{c}(\mathrm{a}+1) \mathrm{t}_{\mathrm{d}}^{\mathrm{a}}
$$

where: $\operatorname{ICFCc}\left(t_{d}\right)$ - the intensity of cumulative energy consumption to the mileage $t_{d}, c, a-$ coefficients.

Constants "c" and "a" equations (6) can be derived from data obtained from the use of vehicles in natural operation. Such data are collected by various institutions and individuals. One of a good database is from the website spritmonitor.de [11]. The advantage of this database is not only the large amount of data collected there. but also their widespread (and easy) availability. Data from this database will be used in further consideration.

Figure 3 presents operation data of the SMART Fortwo car No 641784. To determine the coefficients "c" and "a", data from the operation are necessary and sufficient. After calculations, the following results are obtained

$$
\mathrm{c}=0.131752, \mathrm{a}=0.004568
$$

and accordingly

$$
\mathrm{CFC}_{\mathrm{c}}\left(\mathrm{t}_{\mathrm{d}}\right)=\mathrm{ct}_{\mathrm{d}}^{(\mathrm{a}+1)}=0.131752 \mathrm{t}_{\mathrm{d}}^{1.004568}
$$

and

$$
\text { ICFCc }=c(a+1) t_{d}^{a}=0.132354 t_{d}^{0.004568}
$$


Six decimal places of coefficient values look a bit shocking. They were, however, deliberately entered. The author's experience shows that the more accurately the value of coefficients is given, the mathematical model is more adequate. On the other hand, in today's computing calculations, the accuracy of calculations results from the use of values with a much larger number of decimal places. These values are stored in the computer's memory and it does not matter how they are displayed on the screen.

Similarly, the results of the analysis but in the case of a TESLA S car (No. 829324) lead to data

$$
\mathrm{c}=0.193178 \text { and } \mathrm{a}=0.004073
$$

The models adequacy assessment (6) was carried out using the analysis of variance. The results are as follows (Table 2).

Table 2. Results of the analysis of variance to determine the adequacy of the model (6).

\begin{tabular}{|r|r|r|}
\hline & & \\
& SMART Fortwo & TESLA S \\
\hline Multiple R & 0.999620 & 0.999943 \\
\hline Rsquare & 0.999241 & 0.999885 \\
\hline Matched Rsquare & 0.999221 & 0.999883 \\
\hline Standard error & 0.024617 & 0.000314 \\
\hline Observations & 40 & 104 \\
\hline
\end{tabular}

The observations number is in this case the same as the charging number.

The results are amazingly good. It was not expected that the correlation coefficients will be so high (it is worth recalling here that the maximum theoretical value of, for example, the $R$ square $\left(R^{2}\right)$ coefficient is $R^{2}=1$.

It is hardly surprising that the correlation coefficient has such a high value since the "measuring" points lie almost perfectly on the curve of the model.

A graphic illustration of the results obtained is shown in Figures 4 and 5. In this form presented results can be treated as a kind of energy footprint of the defined vehicle.

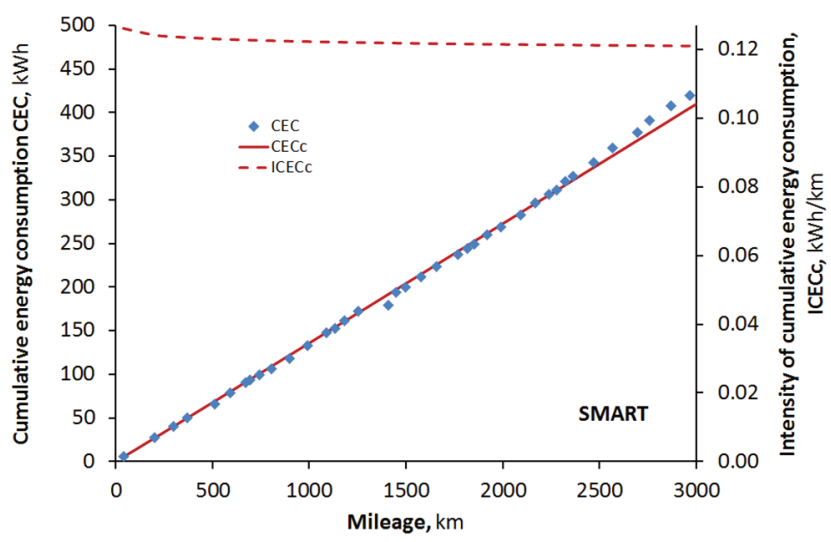

Fig. 3. Energy footprint of SMART Fortwo car No. 641784

Both curves (CFCc and ICFCc) give the impression that they are straight lines. However, when analyzing values of coefficients, it must be clearly stated that they are curves, and only in some cases (as presented here) quasi straightlines.
Both drawings show that the average intensity of cumulated electricity consumption can be reported relative to one kilometer of the car's mileage.

The intensity of cumulative energy consumption for both car are in Table 3 given.

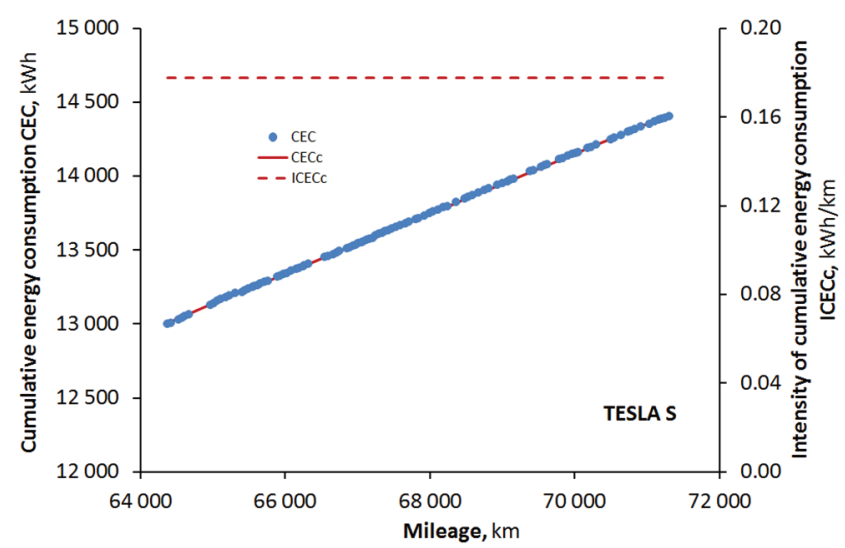

Fig. 4. Energy footprint of TESLA S car No. 829324

Table 3. Intensity of cumulative energy consumption data for analyzed car

\begin{tabular}{|l|r|r|}
\hline Car & Car No. & ICEC $[\mathrm{kWh} / \mathrm{km}]$ \\
\hline SMART Fortwo & 641784 & 0.1420 \\
\hline TESLA S & 829324 & 0.2019 \\
\hline
\end{tabular}

If the data on the ICECc for more cars are known, then can be achieve the values for a given type of car. The relevant data are shown in Table 4.

Table 4 Intensity of cumulative energy consumption statistical parameters for analyzed cars types

\begin{tabular}{|r|r|r|}
\hline Statistical parameters & SMART Fortwo & TESLA S \\
\hline Average & $\mathbf{0 . 1 6 4 7}$ & $\mathbf{0 . 2 0 8 3}$ \\
\hline Standard error & 0.0039 & 0.0039 \\
\hline Median & 0.1624 & 0.2093 \\
\hline Dominant & 0.1554 & 0.2111 \\
\hline Standard deviation & 0.0233 & 0.0315 \\
\hline Kurtosis & 0.0005 & 0.0010 \\
\hline Slant & 0.7362 & 3.1771 \\
\hline Range & 0.8955 & 0.4176 \\
\hline Minimum & 0.1023 & 0.2177 \\
\hline Maximum & 0.1250 & 0.1109 \\
\hline Sum & 0.2273 & 0.3286 \\
\hline Counter & 5.9294 & 13.5366 \\
\hline Confidence level for the average & 36 & 65 \\
\hline (95.0\%) & & \\
\hline & 0.0079 & 0.0078 \\
\hline
\end{tabular}

Table 4 shows that 36 SMART Fortwo cars and 65 TESLA S cars were analyzed. Obviously, average cumulative energy intensity values are different than those for only two cars. It is interesting that the confidence interval for the average is relatively wide but almost the same for both types of cars. However, the standard deviations for both types of vehicles differ significantly.

The analysis of kurtosis and skewness indicates that the potential statistical distributions for describing both sets of data will differ significantly. It is likely to use the normal distribution for describing the SMART Fortwo data, but the TESLA S car data will have to be described in a different statistical distribution. 
With the data from Tables 1 and 4 is possible to achieve of $\mathrm{CO}_{2}$ emission in each country of EU. The calculations results are here in the Fig. 5 given.

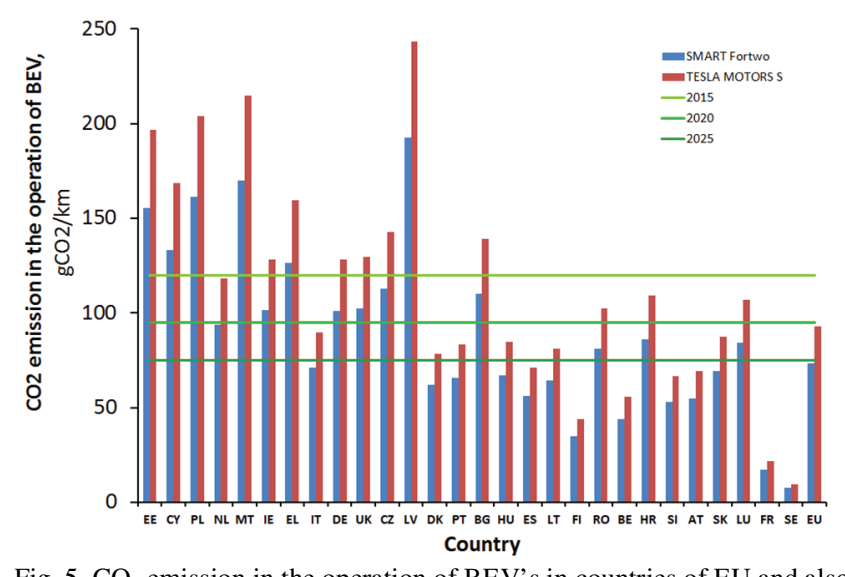

Fig. 5. $\mathrm{CO}_{2}$ emission in the operation of BEV's in countries of EU and also average for $\mathrm{EU}$

For the comparison in Figure 5 are the maximum emission of $\mathrm{CO}_{2}$ for car fleets in EU for next year's showing. These values are correct for NEDC but for the WLTP test they are only slightly lower.

The results of the calculations proved to be in line with expectations. On average, in the European Union it is already worthwhile to use electro vehicles (BEV's) because $\mathrm{CO}_{2}$ emissions are within the limits of the adopted standards for 2020. The use of small BEV's already allows to meet the standards for 2025 today.

If the average is good it means that in some states of the union is better (much) than in others where in terms of emissions there is still a lot to do.

Figure 5 shows that in some countries, in order to get closer to the standards for 2020, it would be necessary to reduce $\mathrm{CO}_{2}$ emissions by at least a half. This means that although any action is aimed at reducing energy consump- tion of vehicles have a sense, then the main burden of change should concern the change in energy production and distribution.

\section{Conclusions}

This paper presents two important methods for assessing the emission of electric vehicles

- an emission assessment method for generating and supplying electricity to battery charging points,

- a method of assessing energy consumption in the natural use of vehicles.

Both methods are shown in a static application - although there are no contraindications to use them together in dynamic applications, including emission forecasting.

The method of using both methods is presented on the example of $\mathrm{CO}_{2}$ emission assessment resulting from the operation of battery electric vehicles.

Simulation research shows that there are already countries in the EU where the operation of electric vehicles makes sense. Especially when it concerns $\mathrm{CO}_{2}$ emissions. Emissions below the standards for 2025 can be obtained there. Unfortunately, in many EU countries, the operation of $\mathrm{BEV}$ is associated with increased (in relation to presentday) $\mathrm{CO}_{2}$ emissions.

Because the high emission, in the first place, corresponds to the use of energy coming from non-renewable resources, together with excessive $\mathrm{CO}_{2}$ emissions probably occur excessive emissions of nitrogen and sulfur oxides and a number of others, as well as heavy and radioactive metals. Even if the plants are equipped with appropriate exhaust gas treatment systems, there are no systems operating with $100 \%$ efficiency - therefore emissions cannot be avoided.

Without changing the energy policy, and in particular the energy mix, introducing e-mobility is problematic.

The methods to the assessment of the political solutions are available and are here now presented.

[8] SITNIK, L. Theory of cumulative fuel consumption and example for its application. Trans \& MOTAUTO' 14: XXII international scientific-technical conference: proceedings. Varna, 23-24.06.2014.

[9] SITNIK, L. Theory of cumulative fuel consumption by LPG powered cars. Journal of KONES. 2015, 22(4), 275-280.

[10] Spritmonitor.de https://www.spritmonitor.de/de/detailansicht/628759.html

[11] TIETGE, U., DÍAZ, S., MOCK, P. et al. From laboratory to road. A 2016 update of official and 'real-world' fuel consumption and $\mathrm{CO}_{2}$ values for passenger cars in Europe. WHITE PAPER November 2016, www.theicct.org

Prof. Lech J. Sitnik, DSc., DEng. - Faculty of Mechanical Engineering, Wroclaw University of Science and Technology.

e-mail:lech.sitnik@pwr.edu.pl 